\title{
Legislações municipais sul-rio-grandenses e suas interpretações acerca da gestão democrática
}

\author{
Rosimar Serena Siqueira Esquinsani ${ }^{1}$ \\ https://orcid.org/0000-0002-6918-2899
}

\section{Resumo}

Referenciar a gestão democrática do ensino público é compulsório em legislações educacionais, considerando a previsão do princípio na Constituição Federal de 1988. Mas, que outros elementos são apresentados em legislações infraconstitucionais, para a visibilidade e materialização de tal princípio? Como as legislações locais interpretam o princípio? Este texto discute registros de gestão democrática do ensino público apresentados em legislações locais, a partir do exame de leis afetas nas redes municipais dos 45 municípios sul-rio-grandenses com população acima de 50 mil habitantes. Abraçando uma metodologia analítico-reconstrutiva, os documentos foram examinados a partir do procedimento da análise de conteúdo, utilizando-se a técnica da análise temática, com destaque para as unidades de significação. Ao examinar as legislações locais, indica-se a compreensão particular e a prática de mecanismos de gestão democrática. Como conclusão, as legislações examinadas informam movimentos e intenções do legislador local em razão da demanda pela gestão democrática como princípio. Tais documentos apresentam o princípio caraterizado por três dimensões: a ampliação e qualificação dos fóruns decisórios; o respeito pela comunidade escolar, seus sujeitos e processos, bem como a relativa autonomia financeira, com repasses de verbas e flexibilização burocrática, repassada ao coletivo escolar como forma de controle social.

Palavras-chave: Gestão Democrática; Legislações Municipais; Municípios Sul-Rio-grandenses.

\begin{abstract}
Referencing the Democratic Management of public education is compulsory in educational legislations, considering the provision of the principle in the Federal Constitution of 1988. But, what other elements are presented in infraconstitutional legislation, for the visibility and materialization of such principle? How do local laws interpret the principle? Therefore, the text discusses records of democratic management of public education presented in local legislations, from the examination of laws affecting the municipal networks of the 45 municipalities of Rio Grande do Sul with population over 50 thousand inhabitants. Embracing an analytic-reconstructive methodology, the documents were examined from the content analysis procedure, using the thematic analysis technique, highlighting the meaning unit. In examining local laws, particular understanding and practice of democratic management mechanisms is indicated. In conclusion, the legislations examined inform the local legislator's movements and intentions because of the demand for democratic management as a principle, driven by local legal-normative documents. Such documents present the principle characterized by three dimensions: the expansion and qualification of decision-making forums; respect for the school community, its subjects and processes, as well as relative financial autonomy, with transfer of funds and bureaucratic flexibility, passed on to the school collective as a form of social control.
\end{abstract}

Keywords: Democratic management; Municipal laws; Municipalities of Rio Grande do Sul.

Doutora em Educação. Professora e Pesquisadora do Programa de Pós-Graduação em Educação da Universidade de Passo Fundo/PPGEdu/UPF. E-mail: rosimaresquinsani@upf.br 


\section{Introdução}

Referenciar genericamente a gestão democrática do ensino público é quase compulsório em legislações educacionais, considerando a previsão desse princípio na Constituição Federal de 1988. Mas, que outras referências ou elementos são apresentados em legislações infraconstitucionais, com o condão de contribuir para a efetiva materialização de tal princípio? Como as legislações locais interpretam e dão visibilidade e materialidade ao princípio?

Na direção de respostas a questões como as mencionadas, a academia tem se dedicado há algum tempo na fixação de definições para a gestão democrática, tanto através da produção científica, quanto da atuação em arenas políticas. Tal esforço, legitima e sustenta a crença de que o debate científico e acadêmico pode garantir visibilidade a temas relevantes que compõem a agenda educacional.

Este texto discute mecanismos e estruturas de gestão democrática do ensino público apresentados em legislações locais, a partir do exame de leis municipais sobre o tema nas redes municipais dos 45 (quarenta e cinco) municípios sul-rio-grandenses com população acima de 50 mil habitantes (IBGE, 2019), em uma representação de $8,8 \%$ do total dos municípios gaúchos.

Os documentos que constituíram o corpus documental deste estudo são oriundos da base normativa de cada um dos 45 (quarenta e cinco) municípios, entendidos como artefatos legais que representam a capacidade política dos municípios de legislar sobre suas demandas de maneira autônoma (leis e pareceres/resoluções locais), capturado de site dedicado à compilação de leis municipais (LEIS MUNICIPAIS, 2019) ou, quando não presentes neste site, diretamente na página da Prefeitura Municipal.

O recorte empírico deste estudo se justifica pelo reconhecimento do papel político dos municípios maiores, visto serem centros regionais e potenciais disseminadores de concepções e práticas em relação à administração de redes públicas de ensino. Todavia, cumpre indicar que o Rio Grande do Sul é um estado formado, em sua grande maioria, por pequenos municípios, sendo que 330 municípios gaúchos são considerados de pequeno porte (menos de 10 mil habitantes), o que equivale a $66 \%$ do total de municípios do estado.

Em relação ao estudo das leis locais/municipais, como espaço de construção de sentidos e de ações na gestão escolar, é necessário considerar que “existem, no campo da educação, as políticas de gestão produzidas em múltiplos espaços/tempos e que estas estão em constantes negociações umas com as outras" (ABDIAN; ANDRADE; PARRO, 2017, p. 738), no espaço das negociações e singularidades da prática entre o local / nacional.

No intuito de compor o corpus documental deste estudo, foram selecionadas leis e decretos exarados pelos executivos municipais dos 45 municípios, bem como, quando pertinentes, pareceres, resoluções e/ou notas técnicas consignadas pelo Conselho Municipal de Educação dos municípios selecionados para a pesquisa. A busca no site e/ou nas páginas das Prefeituras, considerou as expressões ‘Gestão da Educação' e 'Gestão Democrática'.

Deliberadamente não foram utilizadas as leis dos Planos Municipais de Educação pois que, a partir de vasto levantamento já realizado (LAUER; ESQUINSANI, 2018), pode-se afirmar que não há variações significativas acerca do conceito e dos mecanismos de Gestão Democrática do Ensino Público em Planos Municipais de Educação sul-rio-grandenses. Os mesmos são, em sua esmagadora maioria, convergentes (quando não cópias quase literais) do Plano Nacional de Educação (Lei 13.005/2014). Tal constatação fortifica a busca por outras pistas sobre o tema, em outras bases legais que não os PMEs. 
Para cumprir o objetivo de apresentar e discutir mecanismos e estruturas de gestão democrática do ensino público apresentados em legislações locais, a pesquisa que deu origem ao texto em tela foi realizada, portanto, prioritariamente em base documental (legislações municipais) e, subsidiariamente, em base bibliográfica (revisão temática), pautada por uma metodologia analítico-reconstrutiva materializada por meio da descrição, categorização, exame e reconstrução de argumentos, apresentando potenciais subsídios ao debate sobre o princípio da Gestão Democrática do ensino público. Os textos legais foram examinados a partir do procedimento da análise de conteúdo, compreendida como “[...] um conjunto de técnicas de análise das comunicações, que utiliza procedimentos sistemáticos e objetivos de descrição do conteúdo das mensagens” (BARDIN, 2007, p. 38), utilizando-se a técnica da análise temática, na qual o “[...] tema é a unidade de significação que se liberta naturalmente de um texto analisado, segundo critérios relativos à teoria que serve de guia à leitura" (BARDIN, 2007, p.105).

Cumpre informar que o texto apresentado é parte integrante de um contexto amplo de pesquisa, que objetiva contribuir para a discussão de políticas e mecanismos institucionais de gestão democrática da educação básica em redes e sistemas públicos de ensino, enquanto pauta relevante na composição da agenda educacional.

\section{Discussões sobre gestão democrática do ensino público [1]}

A Constituição de 1988 anotou, no plano do registro formal, inegáveis conquistas sociais e políticas “ombreando-nos com os países mais contemporâneos” (CURY, 1998, p. 50). No escopo legal, expressam-se avanços substanciais, tais como "a igualdade jurídica entre homem e mulher, a condenação da tortura, a liberdade de consciência e expressão, a liberdade de associação, a garantia do consumidor, o racismo como crime inafiançável, entre outros" (CURY, 1998, p. 50), tais avanços figuram também no campo da educação. Dentre os avanços formalizados na Constituição no campo educacional, consta pela primeira vez em uma Carta Magna, a previsão da Gestão Democrática como princípio do ensino público.

Nessa direção, "uma nova ordem constitucional representa sempre a projeção de uma expectativa de virem a se realizar alguns de seus princípios e traz a esperança de que possamos chegar a um regime democrático com o funcionamento pleno das instituições democráticas” (CURY, 1998, p. 49). Assim, na projeção de expectativas em relação à educação nacional, a Gestão democrática parece ter muito a colaborar.

Porém, mais de 30 anos após a Constituição Federal de 1988, ainda há a possibilidade concreta que uma lei infraconstitucional e regulamentadora, ao mencionar o termo 'gestão democrática', não conduza necessariamente à execução ou formalização de tal princípio, sendo necessário investigar mais detalhada e pormenorizadamente o escopo legal. Por conta disso, parece ser imprescindível identificar os mecanismos que, explícita ou implicitamente, garantem a criação e fortalecimento de práticas de gestão democrática, bem como os mecanismos que acionem esse princípio e os suportes que o garantem.

Isso porque um dispositivo jurídico-normativo no campo educacional pode ser definido como a "expressão dos interesses de uma classe ou coalizão de classes, esses interesses, materializados nos objetivos e fins de ensino só podem ser analisados na realidade e avaliados de acordo com o seu maior ou menor desvio das atenções originais, vários anos depois" (FREITAG, 1986, p.59). Ou seja, é considerando o hiato da lei e a prática real que podemos inferir à sua efetividade legal. 
Parte-se, pois, do pressuposto que os mecanismos de gestão são constituídos por espaços legitimados em diferentes níveis (por leis e/ou arranjos jurídicos e ações organizadas), caracterizados por desempenharem papel central em processos de gestão democrática. Portanto, ao selecionar e examinar legislações municipais, é possível destacar anotações e inferências relacionadas ao tema, que indiquem a compreensão e a prática efetiva de mecanismos de gestão democrática.

As leis nacionais reguladoras - Constituição Federal de 1988, a LDB e o Plano Nacional de Educação, notadamente -, não definiram o significado, a extensão e todos os mecanismos (ou natureza desses mecanismos) para a implementação do princípio de Gestão Democrática do ensino público. Tais leis furtaram-se de um detalhamento que 'amarrasse' ou indicasse nacionalmente a Gestão democrática.

Se a Constituição de 1988 não fornece maiores indicativos sobre o que constituiria uma Gestão Democrática, a LDB 9.394/1996, consegue ser um pouco mais orientativa em relação ao princípio, estabelecendo que:

\footnotetext{
Art. 14. Os sistemas de ensino definirão as normas da gestão democrática do ensino público na educação básica, de acordo com as suas peculiaridades e conforme os seguintes princípios:

I - participação dos profissionais da educação na elaboração do projeto pedagógico da escola;

II - participação das comunidades escolar e local em conselhos escolares ou equivalentes (BRASIL, 1996, p. 1).
}

Portanto, na LDB há a relação de sinônimo ou emparelhamento entre Gestão Democrática e participação, que remete a duas instâncias: a participação dos profissionais da educação na elaboração do projeto pedagógico da escola e à participação das comunidades, escolar e local, em conselhos representativos.

O Plano Nacional de Educação, Lei 13.005/2014, é um pouco mais abrangente ou detalhista. A meta 19 é toda afeta à Gestão Democrática, explicitando o seguinte:

Meta 19: assegurar condições, no prazo de 2 (dois) anos, para a efetivação da gestão democrática da educação, associada a critérios técnicos de mérito e desempenho e à consulta pública à comunidade escolar, no âmbito das escolas públicas, prevendo recursos e apoio técnico da União para tanto (BRASIL, 2014, p. 1).

As 08 (oito) estratégias subsequentes a essa meta trazem quatro focos para consecução da 'efetivação da gestão democrática da educação': o fortalecimento de colegiados, nas estratégias 19.2; 19.3; 19.4 e 19.5, a participação, designadamente na estratégia 19.6, a autonomia pedagógica, administrativa e de gestão financeira, na estratégia 19.7 e, por fim, o zelo para com a especificidade da gestão escolar (formação e/ou eleição de diretores), nas estratégias 19.1 e 19.8 .

De tal modo, a não existência de uma norma nacional explicativa ou, em sua existência, amparada apenas em adjetivos e poucos elementos concretos - como no caso da LDB 9.394/1996 e do Plano Nacional de Educação, Lei 13.005/2014 -, deixa aberta a possibilidade de caminhos que podem, inclusive, contrariar compreensões de democracia.

Há, todavia, a convergência de algumas definições e tópicos coincidentes, especialmente na atual LDB e no coevo Plano Nacional de Educação. Tais convergências e coincidências, avigoram certo consenso acerca do tema, fortalecendo a caracterização da Gestão democrática a partir de critérios como participação, autonomia, diálogo, respeito, coletividade e colegiados.

No que tange à participação da academia no debate - através das pesquisas acerca do tema, há um "suposto por-vir democrático [que] parece ainda não vingado, ao menos na investigação científica" (SOUZA, 2017, p. 14). 
Justo por tal 'espera', “a pesquisa caminha mais próxima dos casos empíricos, relatando casos de democratização da gestão escolar e, em muitas vezes, normatizando ou prescrevendo as formas pelas quais as escolas devem se orientar para alcançarem aquele por-vir" (SOUZA, 2017, p. 14). O mesmo se aplica à gestão democrática em redes de ensino, que ainda caminham entre a (in)definição constitucional e infraconstitucional e as brechas possíveis e compreensíveis pelos legisladores locais.

Já no campo da teorização, vários autores têm se dedicado a definir conceitualmente a Gestão Democrática, ciente de que esta

[...] é uma complexa categoria político-educativa, uma construção social que não dispensa a análise dos contextos históricos, dos projetos políticos e da correlação de forças em que ocorre, para além de envolver dimensões teóricas e conceituais que vão desde as teorias da democracia e da participação, até às teorias organizacionais e aos modelos de governação e administração das escolas e respectivos sistemas escolares (LIMA, 2014, p. 1069-1070).

A citada complexidade não impede que aproximações sejam realizadas, de forma a definir, com contornos mais ou menos claros, os princípios que orientam a prática de uma Gestão Democrática do ensino público, sublinhada por Souza (2009, p. 125-126) como:

[...] um processo político no qual as pessoas que atuam na/sobre a escola identificam problemas, discutem, deliberam e planejam, encaminham, acompanham, controlam e avaliam o conjunto das ações voltadas ao desenvolvimento da própria escola na busca da solução daqueles problemas. Esse processo, sustentado no diálogo, na alteridade e no reconhecimento às especificidades técnicas das diversas funções presentes na escola, tem como base a participação efetiva de todos os segmentos da comunidade escolar, o respeito às normas coletivamente construídas para os processos de tomada de decisões e a garantia de amplo acesso às informações aos sujeitos da escola.

Trata-se, ainda, de um conceito que não se constitui, se sustenta ou se reduz apenas à força da sua semântica ou de sua ligação histórica com movimentos democráticos, pois:

[...] reconhecer o forte simbolismo político da gestão democrática, a sua genealogia revolucionária e as suas ligações privilegiadas à democracia participativa não implica, em caso algum, deixar de estudar as suas dimensões teóricas, de debater as suas realizações práticas (LIMA, 2014, p. 1070).

Parece lícito supor que o que constitui e legitima a Gestão Democrática são as práticas sociais efetivas sendo, portanto, necessário tracejar, claramente, o que a materializa, buscando evidências legais e/ou cotidianas dessas práticas sociais e dos mecanismos estabelecidos e acionados para a sua efetivação.

\section{Discussões sobre as legislações municipais examinadas}

Quando uma lei é promulgada, compreendemos que estão expressos consensos, frutos de estratégias e deliberações políticas, de posições e tensionamentos que resultaram naquele determinado texto legal, uma vez que “a lei é antes de tudo uma síntese, um produto de embates” (ADRIÃO; CAMARGO, 2001, p. 70).

Portanto, pesquisas com legislações locais (no caso, municipais) exigem duas compreensões: a) que aquela foi a norma possível, oriunda do consenso produzido naquele contexto e naquela situação particular, sendo, portanto, difícil replicar ou generalizar a mesma perspectiva para contextos diversos; e b) que a lei, em si, não garante a exequibilidade de um princípio. De tal modo, 
[...] ainda que represente um avanço, a simples presença no texto legal de quaisquer medidas democratizadoras não implica a sua execução. Eis parte da ambiguidade que acompanha as conquistas no plano da lei: as contradições entre o proposto e o implementado (ADRIÃO; CAMARGO, 2001, p. 70).

Assim, quando o conteúdo de uma lei (a letra da lei) menciona o termo 'gestão democrática' não significa, necessariamente, a execução ou formalização de tal princípio. É preciso identificar, na mesma lei, os mecanismos que efetivamente podem acionar tal princípio, bem como os suportes que o garantem.

Acredita-se que a possibilidade de identificação de tais mecanismos pode se dar com maior facilidade junto às leis de um município. Isso porque a legislação municipal afeta à educação representa um ordenamento jurídico específico, apoiado em peculiaridades e condições idiossincráticas, capazes de traduzir e de se aproximar efetivamente do cotidiano dos sistemas e redes de ensino.

Localizar a gestão democrática a partir de leis municipais parece possível, pronunciável e materializável, posto que:

\begin{abstract}
Toda vez que se propõe uma gestão democrática da escola pública [...], isso acaba sendo considerado como coisa utópica [...]. A palavra utopia significa o lugar que não existe. Não quer dizer que não possa vir a existir. Na medida em que não existe, mas ao mesmo tempo se coloca como algo de valor, algo desejável do ponto de vista da solução dos problemas da escola, a tarefa deve consistir, inicialmente, em tomar consciência das condições concretas, ou das contradições concretas, que apontam para a viabilidade de um projeto de democratização das relações no interior da escola (PARO, 2016, p.13).
\end{abstract}

Portanto, ainda que a lei de um município seja o produto dos consensos possíveis em conjunturas datadas, essa lei local será, possivelmente, a que mais impactará na vida cotidiana dos cidadãos, uma vez que lhes fala mais proximamente, garante sua singularidade e informa as condições precisas da execução de um ordenamento jurídico, no caso, do princípio de gestão democrática.

Os municípios são espaços políticos onde talvez seja possível avançar e concretizar uma gestão que se pretende democrática, pois

[...] em se tratando do município, ente federativo com responsabilidade de ordenar o desenvolvimento social, importa aqui destacarmos seu papel no estabelecimento de políticas públicas específicas, o que inclui as relacionadas à democratização da gestão do ensino público na educação básica (NARDI, 2018, p.128).

Analisando o corpus documental oriundo da base normativa de cada um dos 45 (quarenta e cinco) municípios sul-rio-grandenses com população acima de 50 mil habitantes, foi possível chegar a alguns indicadores concretos acerca da materialização da Gestão Democrática do Ensino Público.

Quando descrevemos o corpus empírico - quadro 01 apresentado na sequência -, chegamos a um quadro de documentos jurídico-normativos que embasaram a pesquisa e que é composto, em sua maioria, por leis exaradas pelo poder executivo municipal. Há, todavia, um conjunto de 15 decretos que regulamentam determinados pontos da lei, referendando a força normativa do poder local. 
Quadro 01 - Informações sobre os municípios componentes da amostra

\begin{tabular}{|c|c|c|c|c|}
\hline Posição & Município & Faixa Populacional & Região & $\begin{array}{l}\text { Documentos } \\
\text { examinados }\end{array}$ \\
\hline 1 & Porto Alegre & $>1.400 .000$ hab. & Metropolitana & 04 Leis \\
\hline 2 & Caxias do Sul & $>500.000$ hab. & Nordeste & 02 Leis \\
\hline 3 & Canoas & $>300.000$ hab. & Metropolitana & 02 Leis \\
\hline 4 & Pelotas & $>300.000$ & Sudeste & 02 Leis \\
\hline 5 & Santa Maria & $>200.000$ hab. & Centro Ocidental & 02 Leis \\
\hline 6 & Gravataí & $>200.000$ & Metropolitana & $\begin{array}{l}02 \text { Leis } \\
01 \text { Decreto }\end{array}$ \\
\hline 7 & Viamão & $>200.000$ & Metropolitana & 02 Leis \\
\hline 8 & Novo Hamburgo & $>200.000$ & Metropolitana & $\begin{array}{l}01 \text { Lei } \\
01 \text { Decreto }\end{array}$ \\
\hline 9 & São Leopoldo & $>200.000$ & Metropolitana & $\begin{array}{l}01 \text { Lei } \\
01 \text { Decreto }\end{array}$ \\
\hline 10 & Rio Grande & $>200.000$ & Sudeste & 02 Leis \\
\hline 11 & Alvorada & $>200.000$ & Metropolitana & 02 Leis \\
\hline 12 & Passo Fundo & $>200.000$ & Noroeste & 04 Leis \\
\hline 13 & Sapucaia do Sul & $>100.0000$ hab. & Metropolitana & 02 Decretos \\
\hline 14 & Santa Cruz do Sul & $>100.0000$ hab. & Centro Oriental & 02 Leis \\
\hline 15 & Cachoeirinha & $>100.0000$ hab. & Metropolitana & 03 Leis \\
\hline 16 & Uruguaiana & $>100.0000$ hab. & Sudoeste & 02 Leis \\
\hline 17 & Bagé & $>100.0000$ hab. & Sudoeste & 02 Leis \\
\hline 18 & Bento Gonçalves & $>100.0000$ hab. & Nordeste & $\begin{array}{l}02 \text { Leis } \\
01 \text { Decreto }\end{array}$ \\
\hline 19 & Erechim & $>100.0000$ hab. & Noroeste & $\begin{array}{l}02 \text { Leis } \\
01 \text { Decreto }\end{array}$ \\
\hline 20 & Guaíba & $>50.000$ hab. & Metropolitana & 02 Leis \\
\hline 21 & Lajeado & $>50.000$ hab. & Centro Oriental & 02 Leis \\
\hline 22 & Ijuí & $>50.000$ hab. & Noroeste & $\begin{array}{l}01 \text { Lei } \\
01 \text { Decreto }\end{array}$ \\
\hline 23 & Esteio & $>50.000$ hab. & Metropolitana & 02 Leis \\
\hline 24 & Cachoeira do Sul & $>50.000$ hab. & Centro Oriental & $\begin{array}{l}01 \text { Lei } \\
01 \text { Decreto }\end{array}$ \\
\hline 25 & Sapiranga & $>50.000$ hab. & Metropolitana & 02 Leis \\
\hline 26 & $\begin{array}{l}\text { Santana do } \\
\text { Livramento }\end{array}$ & $>50.000$ hab. & Sudoeste & $\begin{array}{l}01 \text { Lei } \\
01 \text { Decreto }\end{array}$ \\
\hline 27 & Santo Ângelo & $>50.000$ hab. & Noroeste & 01 Lei \\
\hline 28 & Alegrete & $>50.000$ hab. & Sudoeste & $\begin{array}{l}01 \text { Lei } \\
02 \text { Decreto }\end{array}$ \\
\hline 29 & Santa Rosa & $>50.000$ hab. & Noroeste & 01 Lei \\
\hline 30 & Farroupilha & $>50.000$ hab. & Nordeste & 02 Leis \\
\hline 31 & Venâncio Aires & $>50.000$ hab. & Centro Oriental & 01 Lei \\
\hline
\end{tabular}




\begin{tabular}{|c|l|l|l|l|}
\hline 32 & Campo Bom & $>50.000$ hab. & Metropolitana & 02 Leis \\
\hline 33 & Camaquã & $>50.000$ hab. & Metropolitana & $\begin{array}{l}01 \text { Lei } \\
01 \text { Decreto }\end{array}$ \\
\hline 34 & Vacaria & $>50.000$ hab. & Nordeste & $\begin{array}{l}01 \text { Lei } \\
01 \text { Decreto }\end{array}$ \\
\hline 35 & Montenegro & $>50.000$ hab. & Metropolitana & 02 Leis \\
\hline 36 & São Gabriel & $>50.000$ hab. & Sudoeste & 01 Lei \\
\hline 37 & Carazinho & $>50.000$ hab. & Noroeste & 02 Leis \\
\hline 38 & Cruz Alta & $>50.000$ hab. & Noroeste & 02 Leis \\
\hline 39 & São Borja & $>50.000$ hab. & Sudoeste & $\begin{array}{l}01 \text { Lei } \\
01 \text { Decreto }\end{array}$ \\
\hline 40 & Parobé & $>50.000$ hab. & Metropolitana & 02 Leis \\
\hline 41 & Taquara & $>50.000$ hab. & Metropolitana & 02 Leis \\
\hline 42 & Canguçu & $>50.000$ hab. & Sudeste & 02 Leis \\
\hline 43 & Capão da Canoa & $>50.000$ hab. & Metropolitana & 01 Lei \\
\hline 44 & Tramandaí & $>50.000$ hab. & Metropolitana & $\begin{array}{l}01 \text { Lei } \\
01 \text { Decreto }\end{array}$ \\
\hline 45 & Estância Velha & $>50.000$ hab. & Metropolitana & 01 Lei \\
\hline & & & & $\begin{array}{l}\text { TOTAL: 93 } \\
\text { documentos }\end{array}$ \\
\hline & & & & \\
\hline
\end{tabular}

Fonte: organização da autora, 2019.

Considera-se, nessa perspectiva, o município como ente dotado de relativa autonomia, com condições concretas de originar e sustentar processos democráticos (também no âmbito de sua rede de ensino) capazes de materializar alguns dos princípios constitucionais, tais como:

A autonomia político-administrativa dá-se pela organização do aparato governamental para o atendimento dos interesses locais, conforme previsto em Lei Orgânica, sem imposição hierárquica dos demais entes federados, desde que respeitados os preceitos constitucionais. A autonomia jurídiconormativa ocorre quando o município é capaz de editar leis próprias, conforme matérias de sua competência estabelecidas nas Constituições Federal e Estadual. A autonomia financeira/tributária é a capacidade de gerir adequadamente os recursos de sua competência, sejam relativos aos tributos municipais ou transferências do Estado ou da União (FLACH, 2019, p. 5).

Os artefatos legais que compõem a base normativa dos municípios conseguem ser mais precisos e detalhados em relação ao princípio, indicando com mais clareza mecanismos e práticas de Gestão Democrática, além de sublinhar referências aos critérios de participação, autonomia, diálogo, respeito, coletividade e colegiados. Tais aspectos estão presentes nas legislações examinadas, em maior ou menor grau ou reforço e através de retóricas e/ ou da previsão de mecanismos que garantam tais critérios.

A título de ilustração, um dos documentos jurídico-normativos locais examinados, prevê que a gestão democrática será concretizada mediante a observação dos seguintes indicadores:

I - autonomia dos estabelecimentos de ensino na gestão administrativo-financeira;

II - participação dos segmentos da comunidade escolar nos processos decisórios em órgãos colegiados;

III - transparência dos mecanismos administrativo-financeiros;

IV - valorização dos profissionais da educação;

V - eficiência no uso dos recursos públicos (BENTO GONÇALVES, 2007, p. 1). 
Assim, no plano discursivo ou do registro formal (a letra da lei), aparentemente todas as legislações municipais examinadas reforçam a ideia de uma Gestão Democrática assegurada como princípio para a administração da rede, sistema de ensino municipal e/ou das escolas partícipes de tal rede/sistema. Todas as leis analisadas referenciam de forma direta ou tangencial - o ordenamento constitucional como suporte para a previsão da gestão democrática do ensino público.

Já no plano material da previsão de mecanismos, há a descrição de instâncias municipais de gestão democrática: Conselhos e Fóruns de educação; Conselho Escolar; Grêmio Estudantil; associações de pais; associações sindicais, além da previsão legal de práticas de gestão democrática: eleições de diretores; reuniões pedagógicas, conselhos de classe, assembleias deliberativas e/ou de prestação de contas, etc.

Em todas as leis examinadas, a previsão ou descrição das instâncias e práticas referidas são acompanhadas por explicações que envolvem algumas definições que, em geral, são constituídas por substantivos como: diálogo, participação e coletivo.

Também de forma ilustrativa, há a remissão a uma das leis locais de Caxias do Sul, que indica a gestão democrática como qualificada e materializada através da participação, coletivização de decisões e cidadania, sendo garantida por meio da:

I - eleição direta para o Conselho Escolar, com participação de todos os segmentos da comunidade escolar, conforme determinações da respectiva lei municipal;

II - eleição direta para a equipe diretiva da escola, com participação de todos os segmentos da comunidade escolar, conforme determinações da respectiva lei municipal;

III - autonomia da comunidade escolar para definir seu projeto político-pedagógico, observada a legislação vigente e os princípios emanados do Congresso Municipal de Educação (CAXIAS DO SUL, 2001).

Em ambos os planos (discursivo e material), há certo hibridismo entre modos de gestão (LEITE; HIPÓLITO, 2011), nos quais um dos mais proeminentes, sobretudo no plano discursivo, é a gestão democrática. Há que se destacar que os modos de gestão são conceituados como:

[...] formas de produzir a organização escolar, incluindo as relações políticas e os mecanismos de poder envolvidos nas práticas pedagógicas da comunidade escolar, as concepções e práticas curriculares, bem como todas as formas de organização do processo de trabalho na escola (LEITE; HIPÓLITO, 2011, p. 536).

No que concerne ao exame mais detalhado das legislações municipais, todos os 45 municípios apresentaram duas ou mais legislações em vigor, que estão relacionadas direta ou indiretamente aos temas de pesquisa, perfazendo um conjunto de 93 leis examinadas.

Do corpus documental constituído, as leis mais alinhadas, vinculadas e explícitas em relação à Gestão Democrática são as leis que normatizam a eleição de diretores, diretamente referidas em 27 municípios dentre os entes da amostra. Disto infere-se o emparelhamento entre gestão democrática e eleição de diretores, como se fossem sinônimos ou necessariamente correlatos, como causa/consequência.

A maior parte dos municípios da amostra nominam as leis de eleições de diretores ou gestores como tal: 'lei de eleição de diretores'. Todavia, no registro formal sobre gestão democrática, foram identificados oito (08) municípios que nominam leis específicas como leis ‘sobre’ ou 'de’ Gestão Democrática, ainda que seus conteúdos sejam similares às demais leis municipais, abordando também a eleição de diretores. Tal constatação reforça a 
inferência ao emparelhamento que o legislador fez, considerando gestão democrática e eleição de diretores como duas faces de um mesmo fenômeno.

Há que se pontuar o risco de tal emparelhamento. Consideramos que a eleição de diretores é, sim, um movimento de gestão democrática. Porém, ele é um dos movimentos, não podendo prescindir de outros tantos movimentos, indicadores, mecanismos e práticas que sublinham e fortalecem a gestão democrática. De tal modo, a gestão democrática não se resume à eleição de diretores, exigindo complementações e práticas que vão muito além do ato de escolher um diretor ou equipe gestora.

Há, ainda, um conjunto grande de legislações - 23 no total -, que emparelham gestão democrática com a criação e fortalecimento de instâncias colegiadas e a regulamentação legal de práticas direcionadas a este fim. Os fóruns apresentados nas legislações locais são, em sua grande maioria (em 19 casos), espaços colegiados de natureza consultiva, deliberativa e fiscalizadora. Em outros quatro documentos legais, os colegiados são apenas de natureza consultiva e fiscalizadora.

As leis municipais examinadas, em geral, atribuem aos colegiados funções consultivas no que concerne aos planos administrativos e a questões pedagógicas. De igual maneira, as leis informam que tais colegiados serão deliberativos em questões financeiras, reservando aos mesmos funções fiscalizadoras em relação ao andamento total da escola ou rede de ensino (questões administrativas, pedagógicas, financeiras, técnicas, etc.).

Exemplarmente, o documento jurídico-normativo local de Canoas assim define as atribuições e a presença de colegiados - mormente Conselhos Escolares - no contexto da gestão democrática:

\footnotetext{
Os Conselhos Escolares exercerão funções mobilizadora, consultiva, deliberativa e fiscalizadora, constituindo-se no órgão máximo de discussão ao nível da escola, nos limites da Legislação Nacional em vigor e compatíveis com as diretrizes e políticas educacionais traçadas pelo Sistema Municipal de Ensino, da seguinte forma:

I - Mobilizadora, buscando a participação e integração da comunidade escolar;

II - Consultiva, em planos e programas administrativos pedagógicos;

III - Deliberativa, em questões financeiras;

IV - Fiscalizadora, em questões administrativo-pedagógicas e financeiras (CANOAS, 2008, p. 1).
}

Além das instâncias colegiadas previstas nas legislações, há a previsão legal de práticas colegiadas como materialidade da gestão democrática. As instâncias são os espaços criados ou referendados para organização colegiada, enquanto as práticas configuram-se como as ações colegiadas com objetivos mais restritos, mas anunciando um caráter democratizante.

Portanto, são exemplos de instâncias colegiadas de gestão democrática constantes nas legislações: Conselhos e Fóruns de educação; Conselho Escolar; Grêmio Estudantil; associações de pais; associações sindicais, entre outros. Da mesma forma, são exemplos de práticas colegiadas de gestão democrática presentes nas leis municipais examinadas: reuniões pedagógicas, conselhos de classe, assembleias deliberativas e/ou de prestação de contas (especialmente no que diz respeito à parte financeira da escola).

Aliás, em menor número, mas ainda suficientemente presente no banco de dados, estão as legislações que fazem referência à relativa autonomia financeira das unidades educativas como critério de gestão democrática. Há um conjunto de 18 legislações que aludem diretamente o repasse de recursos para decisão autônoma das escolas, como condição característica da gestão democrática da rede e/ou sistema municipal de ensino. 
Há, ainda, nos documentos examinados, a explicitação de identidades locais, particularmente no que se refere a três registros legais: a) as diferentes nomenclaturas utilizadas para dar corpo aos sujeitos responsáveis pela Gestão Democrática em âmbito municipal: gestor, diretor, coordenador, supervisor foram, em geral, as nomenclaturas mais utilizadas porém, de forma bastante díspar; b) o registro de especificidades trabalhistas das redes e sistemas de ensino examinados - com previsões de distintas cargas horárias para a gestão, por exemplo ; e, c) características particulares dos processos de provimento e recursos humanos de cada município, como a previsão de diferentes cargos na composição dos quadros das escolas e, em especial, na equipe gestora.

Tais características particulares ou singularidades reforçam a concepção de que políticas educacionais "Não são produtos construídos para serem consumidos em determinado espaço, política não é um texto produzido pelo governo a ser implementado pela escola, ela é marcada por sentidos políticos de formação da própria humanidade" (ABDIAN; ANDRADE; PARRO, 2017, p. 738).

Assim, o documento normativo, que já é a consequência de negociações e contradições, só deixará de ser um 'papel' quando for efetivamente pautado pelos interessados (e endereçados), quando fizer parte da agenda e das ações concretas dos espaços e grupos aos quais se destina.

Por fim, de acordo com a análise das legislações recortadas, a gestão democrática pode ser caracterizada como um mecanismo que garante, ao menos, três dimensões práticas: a ampliação e qualificação dos fóruns decisórios (livre organização dos segmentos, participação), sobretudo na eleição de diretores que é, em muitos casos, emparelhada à própria gestão democrática; o respeito pela comunidade escolar, seus sujeitos e processos (autonomia, descentralização e valorização dos profissionais da educação) e a relativa autonomia financeira, com repasses de verbas e flexibilização burocrática, repassada ao coletivo escolar como forma de controle social (transparência e eficiência em relação às ações e aos recursos).

\section{Conclusão}

Pesquisar legislações impõe certa disciplina ao pesquisador, uma vez que toda lei é indexada a um determinado momento e movimento histórico e a ele presta reverência. Justo por esta razão:

[...] conhecer as leis é como acender uma luz numa sala escura cheia de carteiras, mesas e outros objetos. As leis acendem uma luz importante, mas elas não são todas as luzes. O importante é que é um ponto luminoso ajuda a seguir o caminho. [...] daí acender muitos outros focos de luzes, reconhecer seus espaços e, quando for o caso, modificá-los (CURY, 2002, p. 11).

Portanto, tomadas como objetos históricos, as legislações examinadas informam movimentos e intenções do legislador em razão da demanda pela Gestão Democrática do Ensino Público na forma da lei.

Os 45 municípios cumprem seu papel constitucional e apresentam legislações que regulamentam a gestão democrática em sua rede pública de ensino, materializando mecanismos, espaços e ações para tal modelo de gestão. Reforça-se que há uma necessidade contextual e premente da existência de normais legais que regulamentem a gestão democrática do ensino público em redes e sistemas de ensino, pois partimos da premissa que as leis ordinárias e nacionais não são suficientemente detalhadas no que concerne aos mecanismos e ações específicas de gestão. 
Todos os municípios examinados - através de 93 documentos legais -, informam a gestão democrática como princípio, conduzido por meio de instâncias e práticas descritas nos referidos documentos.

Todavia, algumas constatações são inquietantes e problematizáveis. Dentre as constatações mais inquietantes, salta aos sentidos o emparelhamento entre gestão democrática e eleição de diretores ou gestores escolares, como se o princípio pudesse ser sistematizado ou resumido em uma única materialidade.

Ainda, a partir da análise das leis locais em destaque, surge a gestão democrática como um conceito caraterizado por três dimensões: a ampliação e qualificação dos fóruns decisórios; o respeito pela comunidade escolar, seus sujeitos e processos, bem como a relativa autonomia financeira, com repasses de verbas e flexibilização burocrática, repassada ao coletivo escolar como forma de controle social.

Assim, parece lícito inferir que o que constitui e legitima a Gestão Democrática são as práticas sociais efetivas sendo, portanto, necessárias outras investigações tempestivas que visem tracejar, claramente, o que materializa a Gestão Democrática, buscando evidências cotidianas dessas práticas sociais e dos mecanismos estabelecidos e acionados quando dessas práticas.

Sublinha, por derradeiro, o avanço conquistado pelos municípios, foco da análise, ratificando a necessária regulamentação da Gestão Democrática no âmbito dos territórios municipais.

\section{Referências}

ABDIAN, Graziela Zambão; ANDRADE, Éderson; PARRO, Ana Lúcia Garcia. Sentidos de política e/ de gestão nas pesquisas sobre a escola. Educação e Pesquisa, São Paulo, v. 43, n. 3, p. 727-742, Sept. 2017.

ADRIÃO, T., CAMARGO, R. B. A gestão democrática na Constituição Federal de 1988. In: OLIVEIRA, R. P., ADRIÃO, T. (orgs) Gestão, financiamento e direito à educação: análise da LDB e da Constituição Federal. São Paulo: Xamã, 2001.

BENTO GONÇALVES. Lei $\mathbf{n}^{\mathbf{0}}$ 4.205, de 03 de outubro de 2007. Dispõe sobre a escolha de diretores de escolas municipais e dá outras providências. Disponível em: http://www.bentogoncalves.rs.gov.br/ municipio/legislacao. Acesso em 12 fev. 2019.

BRASIL. Presidência da República. Casa Civil. Subchefia para Assuntos Jurídicos. Constituição da República Federativa do Brasil, 1988. Disponível em: http:/www.planalto.gov.br/ccivil_03/ constituicao/constituicao.htm. Acesso em 10 jun. 2019.

BRASIL. Presidência da República. Casa Civil. Subchefia para Assuntos Jurídicos. Lei 9. 394. Estabelece as diretrizes e bases da educação nacional. Brasília: Casa Civil, 1996. Disponível em: http://www.planalto.gov.br/CCIVIL_03/leis/L9394.htm. Acesso em 10 set. 2019.

BRASIL. Presidência da República. Casa Civil. Subchefia para Assuntos Jurídicos. Lei 13.005, de 25 de junho de 2014. Aprova o Plano Nacional de Educação - PNE e dá outras providências. Disponível em: http://www.planalto.gov.br/ccivil_03/_Ato2011-2014/2014/Lei/L13005.htm. Acesso em 10 set. 2019. 
CANOAS, Lei $\mathbf{n}^{0} 5348$ de 17 de novembro de 2008 - Dispõe sobre a implantação dos Conselhos Escolares nos estabelecimentos de ensino da rede municipal de Canoas e dá outras providências. Disponível em: https://www.leismunicipais.com.br. Acesso em 24 mar. 2019.

CAXIAS DO SUL. Lei $\mathrm{n}^{0}$ 5747, de 22 de novembro de 2001. Cria o sistema municipal de ensino de Caxias do Sul. Disponível em: https://www.leismunicipais.com.br. Acesso em 24 mar. 2019.

CURY, Carlos Roberto Jamil. A educação e a nova ordem constitucional. Revista Nacional de Educação, São Paulo, v. 8, n. 14, p. 5-11, 1998.

CURY, Carlos Roberto Jamil. Legislação educacional brasileira. 2.ed. Rio de Janeiro: DP\&A, 2002

FLACH, Simone de Fátima. A gestão democrática nos sistemas municipais de ensino do Paraná: uma análise a partir dos conselhos municipais de educação. Ensaio: Avaliação e Políticas Públicas em Educação. Rio de Janeiro, 2019, [ahead of print] p. 01-20.

FREITAG, Bárbara. Escola, Estado e sociedade. 6. ed. São Paulo: Moraes, 1986.

IBGE - Instituto Brasileiro de Geografia e Estatística. Panorama Rio Grande do Sul. Disponível em: https://cidades.ibge.gov.br/brasil/rs/panorama. Acesso em 23 mar. 2019.

LAUER, Munir José; ESQUINSANI, Rosimar Serena Siqueira. Relatório Técnico do Projeto Mapa da gestão escolar no Rio Grande do Sul: provimento, democracia e qualidade, FAPERGS - Fundação de Amparo à Pesquisa do Estado do Rio Grande do Sul - Edital: 02/2014 - Pesquisador Gaúcho (Número do processo: 2370-2551/14-6), 2018.

LEIS MUNICIPAIS. Leis dos municípios sul-rio-grandenses. Disponível em: https://leismunicipais. com.br/. Acesso em 22 mar. 2019.

LEITE, Maria C. L.; HYPOLITO, Álvaro M. Modos de Gestão, Currículo e Desempenho Escolar. Revista Espaço do Currículo (Online), v. 3, p. 535-547, 2011.

LIMA, Licínio C. A gestão democrática das escolas: do autogoverno à ascensão de uma pósdemocracia gestionária? Educação e Sociedade. Campinas, v. 35, nº 129, p. 1067-1083, out.- dez., 2014.

NARDI, Elton Luiz. Gestão democrática do ensino público na educação básica: dimensões comuns e arranjos institucionais sinalizados em bases normativas de sistemas municipais de ensino. Educar em Revista, Curitiba, v. 34, n. 68, p. 123-136, Apr. 2018

PARO, Vitor Henrique. Gestão democrática da escola pública. 4a . ed. revista e atualizada. Cortez Editora, 2016. 


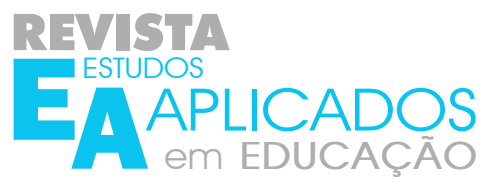

SOUZA, Ângelo Ricardo de. Explorando e construindo um conceito de gestão escolar democrática. Educação em Revista. Belo Horizonte, v.25, n.03, p.123-140, dez. 2009.

SOUZA, Ângelo Ricardo de. As teorias da gestão escolar e sua influência nas escolas públicas brasileiras. Revista de Estudios Teóricos y Epistemológicos en Política Educativa, v. 2, p. $1-19,2017$.

Recebido em: 26/10/2019

Aprovado em: 17/12/2019 